\title{
The Sixth International Conference on Intelligent Environments (IE 10): A Report
}

\author{
Vic Callaghan, Simon Egerton, Achilles Kameas, Ichiro Satoh
}

- The Sixth International Conference on Intelligent Environments (IE 10) was held July 1921 at the Sunway campus of Monash University, Kuala Lumpur, Malaysia. This article presents a report of the conference.
Thtelligent environments (IEs) are everyday settings such as homes, workplaces, or public spaces that are equipped with advanced, networked, computer-based systems that enable better or new lifestyles for people. For example, such technology can lead to design of environments that are more secure, productive, caring, entertaining, or energy efficient. The development of intelligent environments is considered the first and primary step toward the realization of the ambient intelligence vision and requires input from research and contributions from several scientific and engineering disciplines, including computer science, software engineering, artificial intelligence, architecture, social sciences, art, and design. IE conferences create a unique blend of researchers in these disciplines and foster crossdisciplinary discussions, debate, and collaborations.

The Sixth International Conference on Intelligent Environments (IE 10) was held July 19-21 at the Sunway campus of Monash University, Kuala Lumpur, Malaysia. The general chairs were Simon Egerton of Monash University and Ichiro Satoh of the Japanese National Institute of Informatics. Vic Callaghan of the University of Essex, UK, and Achilles Kameas of the Hellenic Open University and Computer Technology Institute, Greece, served as program chairs. This article presents a report of the conference.

The previous five editions of the IE conference have been held at the University of Essex, UK (in 2005), at the National Technical University of Athens, Greece (in 2006), at the University of Ulm, Germany (in 2007), at the University of Washington campus in Seattle, Washington, USA (in 2008), and at the Castelldefels campus of the Technical University of Catalonia, near Barcelona, Spain (in 2009).

This year, a total of 72 papers were selected for inclusion in the conference program, which lasted two and a half days and had two parallel tracks, which in total contained 15 special sessions, on topics that included ambient intelligence and agents, ubiquitous and pervasive computing, context awareness, virtual and mixed reality, human computer interaction, wireless systems, and others. 


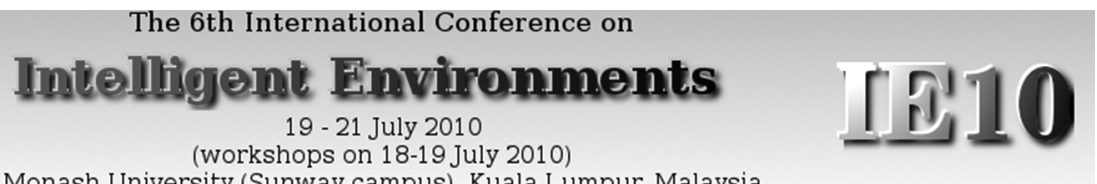

Monash University (Sunway campus), Kuala Lumpur, Malaysia

IE10 was held 19-21 July 2010.

Two special sessions merit special reference. The creative science session, moderated by Brian David Johnson of Intel, built on last year's positive experience. Participants implemented Johnson's science fiction prototyping methodology to present artful interpretations of ideas contained in research publications. The educational prospectives session, moderated by Jason Ng of British Telecom, focused on the potential applications of ubiquitous computing technology in education. It included a round table on the iCampus initiative promoted by the moderator with the collaboration of internationally acclaimed researchers. In addition, this year the conference program included poster papers and a doctoral colloquium. All papers were included in the conference proceedings, which were published in digital format by IEEE.

Four workshops were organized on July 18 . Workshops provide a focused forum for open discussion and cross fertilization of ideas. This year, workshop topics included the application of AI techniques in ambient intelligence, the design of intelligent environments that support well-being, human-centered interfaces for ambient intelligence, and linking immersive virtual environments to physical spaces. The proceedings of the workshops were published as a volume by IOS Press.

In addition to the paper presentations, the conference program included two keynote speeches. Ken Sakamura (University of Tokyo) presented the audience with his longtime experience with TRON intelligent homes, while Dr. Kamal Jit Singh talked about technology innovation in Malaysia and the Far East. Special talks were given by Nathan Shedroff, on learning from science-fiction interfaces, and Sumi Helal, on exploring science-fiction prototypes in persuasive telehealth.

The best paper award, sponsored by IOS Press, was presented to Verena Majuntke and colleagues from the Universitaet Mannheim, Germany, for their paper titled "A Coordination Framework for Pervasive Applications in Multiuser Environments." At the banquet, awards were given to the most faithful members of the intelligent environments community, who have participated in all past editions of the IE conference: Gordon Hunter, from Kingston University, UK, and Michael Schneider from the German research centre for artificial intelligence.
About 100 delegates attended the workshops and the conference. These included representatives from academe, industry, and government laboratories and from specialties including software engineering, artificial intelligence, human factors, architecture, pervasive computing, and even psychology, law, art, and design. Attendees and authors came from the United States, the United Kingdom, Australia, Germany, Spain, Portugal, Japan, Egypt, France, Italy, The Netherlands, Singapore, Switzerland, Malaysia, the Philippines, Mexico, Greece, New Zealand, Sweden, Czech Republic, and Belgium.

The conference was honored by the deputy pro vice chancellor of Monash University's Sunway campus, Walter Wong, and Christopher Messom, head of the School of Information Technology, who attended the opening ceremony of the conference. The Sunway campus of Monash University provided us with all the facilities we needed to make this conference possible.

This year the conference was endorsed for the third time by the American Association for Artificial Intelligence. The Seventh International Conference on Intelligent Environments will take place on July 2011 in Nottingham, UK.

Vic Callaghan is a professor in computer science at the University of Essex, UK. He is the head of the Inhabited Intelligent Environments Group and performs research in the areas of ambient intelligence, ubiquitous computing, intelligent buildings, robotics, and embedded agents.

Simon Egerton is a senior lecturer in the School of Information Technology at Monash University's campus at Sunway, Kuala Lumpur, Malaysia. He is the director of the Intelligent Systems research group and teaches network security and artificial intelligence. His core research area is within robotics and smart device ecologies.

Achilles Kameas is an assistant professor at the Hellenic Open University, Greece, where he teaches software engineering. He is the director of Research Unit 3 at the Computer Technology Institute, where he performs research on the design of ambient intelligence systems, specializing on architectures, middleware, knowledge management, and ontologies.

Ichiro Satoh is an associate professor at the National Institute of Informatics, Japan, where he teaches computer modeling. His research interests include distributed objects, mobile agents, concurrency theory, and naming service for information appliances. 